\title{
Ingenieros del alma \\ los informes sobre canción popular, ensayo y \\ Ciencias Sociales de los Servicios de Inteligencia de la dictadura militar argentina sobre América Latina
}

\author{
'Engineers of the soul' \\ reports from the Argentine military \\ dictatorship's intelligence services on Latin American \\ popular song, essays, and the social sciences
}

\author{
Patricia funes \\ Profesora de la Universidad de Buenos Aires. \\ Investigadora del Consejo Nacional de Investigaciones \\ Científicas y Técnicas - CONICET \\ Doctora en Historia por la Universidad Nacional de La Plata. \\ patfunes@ciudad.com.ar
}

\begin{abstract}
RESUMEN El artículo se propone reconstruir y analizar los informes de los servicios de inteligencia sobre la producción acerca de América Latina durante la última dictadura militar argentina (1976-1983). Partimos de la hipótesis que el concepto "América Latina" es connotado a priori como "subversivo, "comunista", "revolucionario". Lo anterior podría explicar la profusión de informes de inteligencia sobre las ciencias sociales latinoamericanas de los años sesenta y setenta, así como también los centros de estudio, las revistas, e incluso la canción popular encontrados en el Archivo de la ex Dirección de Inteligencia de la Policía de la Provincia de Buenos Aires [DIPBA], fondo privilegiado para la reconstrucción sobre las formas y significados de la construcción de la categoría "delincuente subversivo" por parte de los servicios de inteligencia sobre el campo cultural argentino.
\end{abstract}

Artigo recebido em 13/08/2007. Autora convidada. 
Palabras-clave América Latina, Ciencias Sociales; dictadura, servicios de inteligencia

ABSTRACT The paper aims to trace, to reconstruct and to analyze the records of the Intelligence Services regarding the production of Latin-American social sciences in the period 1976-1983. The object "Latin America" is to the services of intelligence a priori associated with and connoting "communist", "revolutionary" or "subversive". All the above led to an exhaustive work of exegesis and research on the production of Latin-American Social Sciences describing a double process: introducing professionalism in politics and political radicalization. The documents found in the Archive of the former Direction of Intelligence of the Police of the Province of Buenos Aires [DIPBA] -(containing reports of other services of intelligence) allow to infer the importance and the degree of "danger" that the dictatorships attributed to this production. This research will analyze reports issued by Intelligence Offices on popular music, essays and, particularly, classic works produced by Latin American Social Sciences.

Key words Latin America, Social Sciences, dictatorship, Intelligence Services

\section{Introducción}

Una tarde muy fría de invierno, el 26 de junio de 1980, la última dictadura militar en Argentina quemó 18 millones de libros del Centro Editor de América Latina (CEAL). El combustible no alcanzaba para hacer arder las "veinticuatro toneladas y media" de papel, según el informe de los servicios de inteligencia. ${ }^{1}$ Esa hoguera delirante se ha convertido en un símbolo de la destrucción sistemática de la cultura que, sin embargo, no comenzaba con el autodenominado Proceso de Reorganización Nacional (1976-1983). La censura de libros y producciones culturales en Argentina tiene una larga y recurrente historia. Probablemente tan larga y recurrente como los seis golpes militares que asolaron el país entre 1930 y 1983. Sin embargo, esa historia quedó eclipsada por el paroxismo de la última dictadura militar que no sólo censuró libros, prohibió ideas, proscribió colores, formas y sonidos, sino también, en el límite, desapareció a sus creadores. La persecución y censura sobre el campo cultural era sólo un aspecto de la cruzada contra el "enemigo interno": el movimiento obrero, el movimiento estudiantil, "los

1 Sobre el tema, véase: INVERNIZZI, Hernán; GOCIOL, Judith. Un golpe a los libros. Represión a la cultura durante la última dictadura militar. Buenos Aires: EUDEBA, 2002. FUNES, Patricia. Los Libros y la Noche: censura, cultura y represión a través de los servicios de inteligencia del Estado (en prensa). 
jóvenes", los partidos políticos, los religiosos que tomaban la "opción por los pobres". Ya está bastante estudiado que la capacidad militar de las organizaciones armadas revolucionarias de los años setenta, estaba vencida en marzo de 1976. Es decir: otros planes acompañaba esa "lucha contra a subversión". O, quizás uno sólo con varias aristas: "disciplinar" los movimientos sociales, "normalizar" la economía para adaptarla a la acumulación de ciertos sectores, infantilizar a la sociedad a través del miedo, clausurar su capacidad creativa e intelectual.

La historiografía argentina ha comenzado a reconstruir y analizar los distintos niveles y alcances de esa experiencia, en un diálogo tensionado con la profusión de trabajos testimoniales que ha puesto en la agenda académica las relaciones entre historia y memoria. ${ }^{2}$ El presente artículo forma parte de una investigación en curso que tiene como objetivo analizar el rol de los servicios de inteligencia en la construcción del "enemigo interno" durante las dictaduras institucionales de las fuerzas armadas en Argentina (1966-1973 y 1976-1983). Más particularmente, reconstruir esa connotación en el campo cultural argentino a partir de los documentos del Archivo de la Ex Dirección de Inteligencia de la Policía de la Provincia de Buenos Aires (en adelante, DIPBA), único archivo de los servicios de inteligencia abierto al público desde octubre de 2003. ${ }^{3}$ Consideramos que las peculiaridades del fondo documental que tratamos hace imprescindible historizar las funciones y lógicas de los servicios de inteligencia, trabajo aún inicial ya que carece de antecedentes historiográficos. Nos interesa marcar ese contexto ya que pensamos que echa luz sobre la entidad de esos documentos originalmente producidos para estigmatizar y perseguir. Por éso, en la primera parte del artículo, recorreremos algunos núcleos de la estructuración de los servicios de inteligencia en la segunda mitad del siglo pasado confrontándolos con las autojustificaciones de los mismos. En una segunda parte analizaremos los informes de los Servicios de Inteligencia de la dictadura militar argentina sobre América Latina, considerada, según nuestra inicial hipótesis de trabajo, a priori "comunista, subversiva, revolucionaria". Ejemplificaremos lo anterior con algunos informes relativos a la canción popular, el ensayo

2 Véase, al respecto, la reciente compilación de FRANCO, Marina y LEVIN, Florencia. Historia reciente. Perspectivas y desafíos para un campo en construcción. Buenos Aires: Siglo XXI, 2007.

3 El 30 de abril de 1998, por Resolución número 9 del Ministerio de Seguridad y Justicia de la Provincia de Buenos Aires, se disolvió la Dirección de Inteligencia de la Policía de la Provincia de Buenos Aires (DIPBA). Organismos de defensa de los Derechos Humanos solicitaron enfáticamente la separación del Archivo de las fuerzas policiales, la protección y salvaguarda de la información y el acceso a la misma. La Justicia impuso un recurso de "no innovar" protegiendo el Archivo. El edificio donde funcionaba la DIPBA y el archivo fueron cedidos por ley provincial n.12642 del año 2000 a la Comisión Provincial por la Memoria. La Comisión Provincial por la Memoria es un organismo público no gubernamental, autónomo y autárquico creado por ley 12483 de la Legislatura de la Provincia de Buenos Aires el 13 de agosto de 2000. Sus miembros provienen de los organismos de Derechos Humanos, de las iglesias, de la justicia, de la Universidad, del mundo sindical y de la cultura y de la legislatura de la provincia de Buenos Aires. 
y la producción de las ciencias sociales latinoamericanas de las décadas de 1960 y 1970.

\section{"Inventing tradition": genealogías e historia de los servicios de inteligencia}

La forma retórica de justificación de los sucesivos golpes de Estado en Argentina fue la auto-unción de las Fuerzas Armadas como "reservorio moral de la Nación" frente a la "demagogia" y la "corrupción" de la política. Construían así su linaje legitimador: nacieron "con la patria", incluso antes que el Estado, fueron los hacedores de la independencia y los garantes últimos de su reproducción. No casualmente, uno de los ideólogos del primer golpe de Estado (1930), el poeta Leopoldo Lugones, expuso ese argumento en el discurso, "La Hora de la Espada", en Lima, durante la conmemoración del Centenario de la Batalla de Ayacucho en 1924. Seis años después escribía la proclama del primer golpe de Estado militar.

Durante la última dictadura militar (1980) mientras el estado terrorista desaparecía, torturaba y se apropiaba de bebés nacidos en cautiverio, la policía bonaerense consideró que cumplía 400 años. Y se decidía a celebrarlo con una publicación. Con ese motivo encargó una historia prologada por el General de Brigada Ovidio Pablo Riccheri quien afirmaba:

Han transcurrido cuatrocientos años de la fundación de la ciudad de La Trinidad y Puerto de Santa María de los Buenos Aires. La Policía es una institución inherente a la propia comunidad. No resulta insensato pretender historiarla desde los Alcaldes de Hermandad hasta nuestros días. ${ }^{4}$

Si la pretensión de remontar los orígenes de la policía al momento mismo de la llegada del conquistador Juan de Garay es un dato que violenta los hechos históricos, mucho más anacrónica e ideológica es la explicación: "Aquella memorable y cristiana fundación fue el preludio de la aurora triunfal de 1810. Roma Imperial, a través de España nos legó una cultura en la síntesis de la fe y de las armas, de la Cruz y la Espada". Hispanismo (una vertiente muy transitada por el nacionalismo integrista argentino) y la pretensión megalómana de ser herederos de un imperio, aparecía resignificada en el contexto de la cerrada defensa de la "civilización occidental y cristiana" de la Guerra Fría, con los componentes doctrinarios de "seguridad nacional" de entonces.

Frente a tanta prosapia, una de sus dependencias, la DIPBA, también forjó sus propios precursores. El mismo año celebró un aniversario más. Es

4 Policía de la Provincia de Buenos Aires. Síntesis histórica de la Policía de la Provincia de Buenos Aires, 1580-1980. 
evidente que la intención era una deliberada construcción conmemorativa ya que el aniversario no guardaba ninguna efeméride concreta (cumplía 24 años). Es más, en los registros del Archivo se encuentran denodados esfuerzos de indagación histórica para establecer el día exacto de su creación que se establece el 3 de agosto. Las FFAA y de seguridad, habiendo "desarticulado" al "terrorismo", probablemente se dirigían a crear consensos "hacia adentro" y "hacia fuera". Más bien autoconsensos en un servicio de inteligencia cuyos informes eran secretos, no así su estructura era legal. La nota sale en la Revista Buenos Aires Policial que si bien era de circulación interna no era "secreta, confidencial y reservada" como los informes de la DIPBA.

El 3 de agosto de 1980, en el edificio de la DIPBA (actual sede de la Comisión Provincial por la Memoria) se inauguraba una galería de retratos de sus directores con discursos solemnes y altisonantes (algo contradictorio con lo "secreto" de sus funciones). En el acto, el Jefe de la DIPBA, Comisario General Enrique Amable Paillard se refirió a la historia de los servicios secretos que retrotrae "a la más remota antigüedad". Muy pero muy remota, ya que no duda en anclar su tradición hasta el Código de Manú. En un contexto más vernáculo, señalaba que los orígenes de los servicios de inteligencia en el Río de la Plata se podían historiar desde el momento en el que "los criollos (...) simulaban ser renegados en los toldos indígenas para mantener informada a la población sobre fechas probables de ataques de malones". ${ }^{5} \mathrm{O}$ también: "quienes obtenían datos de las actividades de los ingleses o contrabandistas que procuraban ganar para su corona las tierras o el comercio del Río de la Plata". Incluso el Comisario General historió "el primer sumario que se hizo en junio de 1807 por contraespionaje o crimen de Lesa Majestad (...) por recibir del capitán de un bergantín inglés correspondencia subversiva para distribuir entre los enemigos de la causa española". ${ }^{6}$ La anacrónica frase "contraespionaje" y "correspondencia subversiva", desnuda esa intencionalidad que señaláramos antes. Muy antiguos orígenes para muy contemporáneas necesidades de legitimidad, ya que, como tal, ese servicio de inteligencia no tenía mucho más de dos décadas de existencia.

La DIPBA se creó con el nombre Central de Inteligencia de la Policía de la Provincia de Buenos Aires, el 3 de agosto de 1956. ${ }^{7}$ Los significados de la creación de esa nueva dependencia de espía política supone, a nuestro juicio, una diferencia cualitativa en la manera de concebir los modos de

5 Se denomina "malones" a las incursiones a caballo, de los pueblos indígenas sobre las ciudades o "fortines" de la frontera, en general con el objetivo de responder al avance de las ciudades sobre sus dominios. Fueron muy frecuentes en el área pampeana en la primera mitad del siglo XIX.

6 Revista Buenos Aires Policial, Año III, 1980, p. 41.

7 La DIPBA tuvo diferentes denominaciones y jerarquías. Hemos tomado el último nombre que tuvo en el momento de su disolución. 
"prevenir" y reprimir la protesta social. Esa diferencia se observa en el nombre Central de Inteligencia. Las dependencias que la precedieron tenían la palabra "orden" en su denominación (División, Departamento o Dirección de Orden "Político", "Público", o "Social", según las épocas). ${ }^{8}$ La denominada Revolución Libertadora (que desalojó del poder a Juan Domingo Perón) estableció por Decreto 3606 del 29 de diciembre de 1955 la disolución de la Dirección de Orden Público y designó a un integrante de las Fuerzas Armadas para reorganizarla. Esa subordinación de la policía a las Fuerzas Armadas es un primer dato en el proceso de colonización y militarización de esa fuerza. El pasaje del concepto de "orden" al de "información" y de éste al de "inteligencia" es otro dato importante. El tercer dato es el año. 1956 es el año del proceso de movilización obrera denominado "resistencia peronista", el año de los fusilamientos de los generales leales a Juan Domingo Perón que se sublevaron contra la Revolución Libertadora y de los fusilamientos civiles que pasaron a la historia bautizados por Rodolfo Walsh como Operación Masacre.

Pensamos que el año 1956 es un nudo gordiano en la estructuración del aparato de inteligencia en la Argentina del siglo XX. En ocho meses se crearon una serie de agencias y se estructura un sistema de coordinación a nivel nacional. En enero de ese año el Poder Ejecutivo Nacional promulgó el decreto 776/56 que creaba la Secretaría de Informaciones de Estado (SIDE). La SIDE tendría como misión "proporcionar al Gobierno Nacional las informaciones necesarias para la mejor conducción del Estado", para centralizar y coordinar la

(...) actividad informativa integral, procediendo a recibir, clasificar, seleccionar, analizar y distribuir entre los organismos competentes todas aquellas informaciones que produzcan los diversos Servicios de Informaciones de las Fuerzas Armadas, los ministerios civiles, las gobernaciones de Provincias y aquellas que obtenga por medios propios. ${ }^{9}$

En abril se creó la Dirección de Informaciones Antidemocráticas (D.I.A.) con el objeto de "reunir y coordinar los distintos organismos de seguridad del Estado: Jefes del Servicio de Inteligencia del Estado (SIDE), Servicio de Informaciones del Ejército (SIE), Servicio de Informaciones Naval (SIN), Servicio de Informaciones Aeronáuticas (SIA), de la Policía Federal, de la Policía Bonaerense. ${ }^{10}$ Era el antecedente directo de lo que años después se llamó Comunidad Informativa, pieza estratégica de la represión en la última

8 Sobre los antecedentes y distintas jerarquías de la DIPBA véase: FUNES, Patricia y JASHEK, Ingrid. La Creación de la Dirección de Inteligencia de la Policía de la Provincia de Buenos Aires [DIPBA]. Puentes, año V, nº.16, Diciembre, 2005.

9 YOUNG, Gerardo. SIDE. La Argentina secreta. Buenos Aires: Planeta, 2006, p. 40

10 Archivo DIPBA, Mesa Doctrina, Dirección de Informaciones Antidemocráticas, Legajos nos.167 y 277 "Comunismo", 1956. 
dictadura militar ya que coordinaba y intercambiaba información, análisis y políticas de persecusión a nivel nacional.

En agosto, se creaba la DIPBA, en la provincia más importante del país. La D.I.A. elaboró un clasificador de personas y organizaciones para distribuir entre "todas las organizaciones informativas del país, a efectos de un encuadre armónico de personas $u$ organizaciones que tengan un antecedente comunista". ${ }^{11}$ El patrón clasificatorio era: "Comunistas: son los afiliados al Partido Comunista, militantes activos y agitadores; actúan en el partido legal y en la ilegalidad (...). Filocomunistas: simpatizantes del comunismo, no se conoce su filiación, no son militantes activos; son propagadores que justamente no se puede identificar exactamente como comunistas. Criptocomunistas: ocultan su verdadera ideología tras otra aparente, actúan en sectores". ${ }^{12}$ Diez años más tarde, frente al primer golpe institucional de las Fuerzas Armadas en Argentina (1966) se creaba la Comisión Asesora para la Calificación Ideológica Extremista (C.A.C.I.E.) dependiente de la SIDE, encargada de la calificación de publicaciones y personas "comunistas". Queremos resaltar la inflación semántica en las denominaciones. Ya no son "comunistas" sino "extremistas". Ese pasaje del "comunista" genérico al "delincuente subversivo" se advierte en la estructura del Archivo. Originariamente ordenado por "mesas", la información de la "Mesa C" (Comunismo) deja de ser relevante hacia finales de los años sesenta, momento en el cual la mesa "DS" ("Delincuente Subversivo") es el lugar por excelencia del registro, incluso más que la mesa "política", "gremial" o "estudiantil".

\section{Ojos sin párpados: la DIPBA y el campo cultural argentino}

Un documento de la DIPBA de 1957, define los universos de su acción. Además de la espía y seguimiento de militantes políticos y sindicales, la expansión del comunismo "en el Agro (...) como así también en los medios intelectuales y artísticos, en especial en los Teatros Independientes". ${ }^{13}$ También recomienda "un estricto control en las Entidades de Bien Público, barriales, etc., donde en los últimos tiempos, se han infiltrado numerosos elementos comunistas". ${ }^{14} \mathrm{Y}$, sobre todo las instituciones educativas:

Teniendo en cuenta que la acción comunista es muy intensa en nuestro medio en las esferas intelectuales, siendo las universidades, los colegios secundarios y establecimientos similares los lugares preferidos por ellos [...] es imprescin-

11 Archivo DIPBA, Mesa Doctrina, Legajo nº.167, p.9.

12 Archivo DIPBA, Mesa Doctrina, Legajo nº.167, p.9.

13 Informaciones que se requieren para el normal funcionamiento del Departamento y la mesa respectiva, 1957. Archivo DIPBA, Mesa C (Comunismo Varios), legajo $n^{\circ} .25$.

14 Informaciones que se requieren para el normal funcionamiento del Departamento y la mesa respectiva. 
dible someter a estos lugares educacionales a una severa aunque discreta vigilancia. ${ }^{15}$

La objetivación de la Guerra Fría en América Latina a partir de la Segunda Declaración de la Habana, imprime a la tradición anticomunista precedente de nuevas misiones y sentidos. La DIPBA afirma:

\begin{abstract}
Desde julio 1960, el comunismo mundial, favorecido por las luchas que por su "liberación nacional" habían iniciado (y en algunos casos completado) numerosos pueblos afroasiáticos, pasa a contar así en América con una base de experimentación e irradiación ubicada en uno de los puntos más sensibles del sistema defensivo hemisférico y en consecuencia de Occidente. Consecuentemente con esa tónica, el PCA deja aparentemente de preocuparse por su propia situación partidaria y todo su aparato, el legal y el ilegal, se dedica a promover la formación de partidos y movimientos de masa cuya bandera será la solidaridad con Cuba revolucionaria. ${ }^{16}$
\end{abstract}

"Sistema defensivo hemisférico", "civilización occidental y cristiana", "infiltración comunista" son frases que denotan la permeabilidad y consubstanciación del ideario de la DIPBA respecto de las premisas de la recientemente aprendida Doctrina de la Seguridad Nacional en las escuelas de contrainsurgencia.

Los actos de solidaridad con Cuba, de repudio al bloqueo, los congresos latinoamericanos, las manifestaciones antiimperialistas (por ejemplo frente a la invasión norteamericana a Santo Domingo), los viajes de militantes políticos, de artistas, de hombres de ciencia o del periodismo, son relevados con particular minuciosidad. ${ }^{17}$

Otro espacio que forma parte del repertorio temático de la investigación es la posible difusión de ideas marxistas a través de medios de comunicación. Un interés casi obsesivo está puesto en las radioemisoras y las "agencias informativas comunistas":

Las agencias informativas comunistas (Tass, la recientemente creada Novedades de Rusia, CTK de Checoslovaquia, DPA de Alemania Oriental, Agencia Rumana de Prensa, actúan a través de representantes a filiales en Argentina (Argenpress, Prela, etc.). Las principales emisoras comunistas (Radio Moscú, Praga, Varsovia, Pekín, Budapest, etc.) aumentan el número de sus transmisiones en español para América Latina y desarrollan cursos que son seguidos con interés en nuestro país. ${ }^{18}$

15 Informaciones que se requieren para el normal funcionamiento del Departamento y la mesa respectiva.

16 Archivo DIPBA, Mesa C (Comunismo Varios), legajo nº.121, p.15.

17 Por ejemplo: Grabaciones en favor de Cuba -difusión música cubana en Bahía Blanca. Legajo n.147; Congreso Continental de Solidaridad con Cuba. Legajo $n^{\circ} .186$; Banderas, carteles comunistas y cubanas izadas en la jurisdicción de la Provincia de Buenos Aires. Legajo n.208; Encuentro Rioplatense de Solidaridad con Cuba. Legajo $\mathrm{n}^{\circ} .246$, entre otros [Mesa "C"].

18 Principales Programas emitidos para América Latina por Radioemisoras de la Cortina de Hierro. Archivo DIPBA, Mesa C (Comunismo) Varios, legajo n.121, p.15, año 1962. Otros ejemplos: Radioestación de Aficionados Cubana. 
Durante la última dictadura militar, la persecución interna sobre los medios de comunicación, estaba menos preocupada por la solidaridad con Cuba o con las radios de la Cortina de Hierro y más por "autores teatrales e intérpretes que, no obstante sus conocidos antecedentes ideológicos negativos, actúan en el Teatro General San Martín y en algunas radios y canales de televisión oficiales", según reza un informe de la Comunidad Informativa de Acción Psicológica, del 7 de julio de 1977. En él se especifica muy desagregadamente a quiénes observar y calificar:

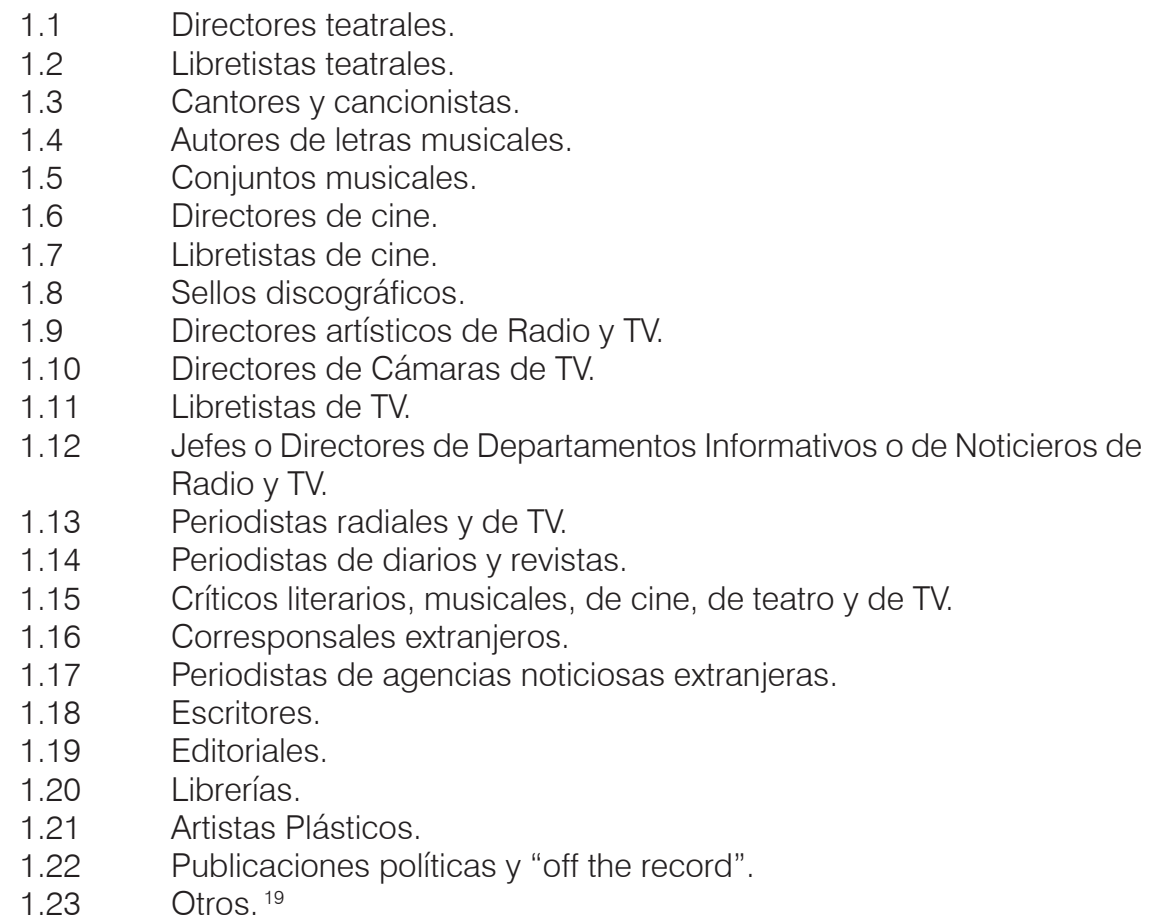

La "Comunidad Informativa" establecía así un "nomenclador" uniforme en todo el país y, con él, activaba una búsqueda en el campo cultural argentino de aquellos con "antecedentes negativos". Si las radioemisoras y las agencias periodísticas del año 1962 estaban consideradas "comunistas", los registros de la espía, persecusión y censura de 1977 están considerados "subversivos".

Legajo $n^{\circ} .157$; Legajo n.257; Radioaficionados comunistas. Legajo n.389; Radio Budapest de Hungría, Legajo $n^{\circ} .403$, entre otros.

19 Antecedentes ideológicos de artistas nacionales y extranjeros que desarrollan sus actividades en la República Argentina. Archivo DIPBA, Mesa Referencia, legajo $\mathrm{n}^{\circ} .17470,1977$. 


\section{América Latina bajo sospecha: de la canción popular a las cien- cias sociales, El disco guerrilla}

Son varios cientos de folios en varios legajos. Fueron producidos por la "Asesoría Literaria del Departamento Coordinación de Antecedentes de la SIDE" durante la última dictadura, dominantemente entre 1976 y 1977 y se encuentran en el Archivo de la DIPBA". ${ }^{20}$ Desconocemos la composición de esa "asesoría literaria". Los informes eran vinculantes, es decir, una vez realizada la exégesis del material por escrito seguramente se elevaba a la Comunidad Informativa que los trataba semanalmente. A partir de ese momento los "indexaba" y, en la mayoría de los casos, elaboraban la recomendación de prohibición a través de un decreto del Poder Ejecutivo.

Los informes son análisis elaborados sobre libros, revistas y discos. Constan de tres partes. En la primera se realiza una descripción externa del soporte (sea éste libro, apuntes mecanografiados, discos, afiches). Ese material tuvo dos orígenes: la mayoría proviene de la Aduana y fue inacautado en el Correo. El otro es probable que sea producto de allanamientos y secuestro de material en domicilios de particulares o de instituciones.

En la primera parte del informe se consigna el nombre del o los autores, o el director de la publicación en el caso de las revistas. La segunda parte es analítica y consta de:

La apreciación, que podía ser de tres grados:

- Carece de referencias ideológicas contrarias a los principios sustentados por nuestra Constitución Nacional;

- Contiene referencias ideológicas que atentan contra los principios de nuestra Constitución Nacional;

- Propicia la difusión de ideologías, doctrinas o sistemas políticos, económicos o sociales marxistas tendientes a derogar los principios sustentados por nuestra Constitución Nacional. ${ }^{21}$

Nótese la sutileza del enunciado "contrarias, atentatorias o derogatorias" no de la Constitución Nacional sino de "los principios que la sustentan", una suerte de "esencia anterior" a la Constitución del Estado que guarda relación con las genealogías antes señaladas. Las Fuerzas Armadas se hacían con una representación de la nación, que es previa a la Constitución Nacional (por ende, anterior a los principios democráticos).

20 Se trata de tres largos legajos de la Mesa Referencia, $n^{\text {os }} .17470,17518,17753$. El primero consta de 364 folios, el segundo de 696 folios y el tercero de 1894 folios. Estos informes de inteligencia, en proceso de análisis, seguramente forman parte de la misma serie encontrada en el denominado Fondo "BANADE" (su nombre proviene del lugar donde fueron encontrados: el sótano del ex Banco Nacional de Desarrollo), analizados y reproducidos parcialmente en INVERNIZZI, Hernán; GOCIOL, Judith. Un golpe a los libros. Represión a la cultura durante la última dictadura militar. Buenos Aires: EUDEBA, 2002.

21 Archivo DIPBA, Mesa Referencia, Legajos ns.17758 y 17753. 
La segunda parte del informe fundamenta la apreciación ordenada en tres partes: "Actitudes o expresiones positivas o de apología, adhesión y/o afirmación hacia", "actitudes negativas o de detracción y/o crítica hacia" y ejemplos (en los que se cita textual párrafos de libros, revistas o letras de canciones). Finalmente se agrega un párrafo de resumen reforzando la apreciación, que de ser la tercera fórmula, se sustentaba (algo circularmente) en la ley de Defensa Nacional a No 20840. ${ }^{22}$

De esa extensa serie documental hemos recortado un universo, aún en proceso de estudio, del que tomaremos algunos casos para su ejemplificación: los informes que se refieren a la producción cultural sobre América Latina.

Partimos de la hipótesis inicial que el concepto "América Latina" fue considerado a priori por los Servicios de Inteligencia como "comunista", "revolucionaria", "subversiva". Esto puede explicar que su mención en centros de estudio, producciones académicas o políticas, ensayos, editoriales incluso, en la narrativa de ficción, fuera objeto de análisis, registro y recomendación de prohibición por parte de los servicios de inteligencia.

El rango de las producciones escritas analizadas es muy amplio: desde novelas y poesías hasta las más emblemáticas obras del ensayo y la sociología clásica latinoamericana. Pero no sólo la producción escrita era secuestrada, incautada y analizada. La música y los discos podían ser tanto o más disolventes que los libros. Desde los oídos de la DIPBA, "la capacidad corrosiva de la música, desde el punto de vista de la "Guerra psicológica marxista" es mayor que la escritura ya que "exige una apreciable cantidad racional de ordenamiento de imágenes de naturaleza distinta". ${ }^{23}$

Un Informe especial sobre discografía elaborado por la $\operatorname{SIDE}^{24}$ en octubre de 1977 plantea la visión orgánico-funcionalista dominante del pensamiento autoritario: la sobredeterminación del grupo sobre el individuo. La música tiene una gran incidencia personal "como consecuencia de la existencia de componentes sugestivos, persuasivos y obligantes en la misma." El argumento se desliza de lo individual a lo colectivo ya que "el instinto gregario permanece en el grupo y los efectos de una experiencia musical son contagiosos". Contagio, enfermedad, "virus comunista". De allí que "mientras

22 La Ley 20840, comúnmente llamada "ley antisubversiva" fue promulgada el 30 de septiembre de 1974 (es decir, antes del golpe militar). Establecía "prisión de tres a ocho años, siempre que el hecho no constituyere un delito más severamente penado, el que para lograr la finalidad de sus postulados ideológicos, intente o preconice por cualquier medio, alterar o suprimir el orden institucional y la paz social de la Nación, por vías no establecidas por la Constitución Nacional y las disposiciones legales que organizan la vida política, económica y social de la Nación".

23 Antecedentes ideológicos de artistas nacionales y extranjeros que desarrollan sus actividades en la República Argentina. Archivo DIPBA, Mesa Referencia $n^{\circ} .17470$, p.288. Los legajos que citamos en este apartado fueron solicitados a la Cámara Federal de Apelaciones de la Plata, ya que-como se ha expresado- la información del período 1976-1983 está bajo su secuestro y sólo acceden a ella los peritos designados por la Cámara.

24 Antecedentes ideológicos de artistas nacionales y extranjeros que desarrollan sus actividades en la República Argentina. Archivo DIPBA, Mesa Referencia, Legajo n.17470, p.289. 
ciertas músicas provocan en el grupo una conducta armónica y ordenada, otras inducen a una falta de dominio general y al desorden". ${ }^{25}$

El discurso autoritario suponía una aceptación acrítica de los mensajes disolventes por parte de sus receptores. Supuesto bastante primario que los estudios sobre comunicación suelen denominar teoría hipodérmica: según ella, los mensajes entran al sujeto receptor como por una inyección; se imprimen en una conciencia desguarnecida, tabula rasa sobre la que, luciferinamente, se modela una visión del mundo. ${ }^{26}$

El informe data con sospechosa precisión la renovación musical en el mundo. Curiosamente, el año 1966. Lo adjudica a dos órdenes de fenómenos que son difíciles de datar con un año preciso. Uno es tecnológico (aparición de la música amplificada) y el otro de mercado (mayor poder adquisitivo de los adolescentes). Si esto es así a nivel mundial, otro tanto ocurre en Argentina el mismo sugerente año:

En nuestro país la actividad discográfica subversiva surge en 1966 cuando el sello grabador Phillips lanza al mercado 3000 discos de larga duración de Canciones con Fundamento que -interpretadas por Mercedes Sosa-, contenían temas disolventes. ${ }^{27}$

El disco Canciones con Fundamento fue grabado y salió al mercado en 1965 y no en 1966 como señala el informe, lo cual vuelve la datación de la "actividad discográfica subversiva" más cercana a la cronología militar que a la dinámica del proceso descripto, ya que el año 1966 es el año del primer golpe de Estado en Argentina inspirado en la Doctrina de Seguridad Nacional. Mercedes Sosa estuvo afiliada al Partido Comunista Argentino, sin embargo, quizás más que esa pertenencia política su "peligrosidad" radicaba en los temas, autores y mensajes de un movimiento musical (el denominado Nuevo Cancionero) que había renovado y acompañado desde el campo musical folklórico los movimientos de denuncia y protesta. La cantante, que ya estaba exiliada del país en 1977 porque había sido seriamente amenazada y prohibida, era la representación musical de América Latina. Había popularizado en la Argentina de los años sesenta y setenta un repertorio que incluía temas, poetas y músicos latinoamericanos identificados con el cambio social: Armando Tejada Gómez, Daniel Viglietti, Alfredo Zitarrosa, Víctor Jara, Violeta Parra, Pablo Neruda, Nicolás Guillén, entre otros. No casualmente, para la DIPBA es el ejemplo más acabado de dos

25 Antecedentes ideológicos de artistas nacionales y extranjeros que desarrollan sus actividades en la República Argentina. Archivo DIPBA, legajo de Referencia n.17470, p. 289.

26 PUJOL, Sergio. En el país de la libertad. Canciones prohibidas. Puentes, año V, nº.15, Septiembre, 2005, Dossier Documentos de la DIPBA.

27 Antecedentes ideológicos de artistas nacionales y extranjeros que desarrollan sus actividades en la República Argentina. Archivo DIPBA, legajo de Referencia nº.17470, p.289. 
conceptos centrales de la ideología dictatorial: el de "ingenieros del alma" y el de "comunicador llave":

La subversión inició una tarea tendiente a lograr que determinados intérpretes y/o compositores, cuidadosamente seleccionados, se transformaran en COMUNICADORES LLAVE, esto es, personas de popularidad relativa en los medios artísticos, cuyo accionar-siguiendo la concepción soviética del rol de escritores y artistas- es el de verdaderos 'ingenieros del alma'. Actuando como 'jerarquías paralelas' (...) procuran imponer un marco de prestigio cultural, sin emitir, en una primera etapa interpretativa, mensajes de 'protesta' demasiado evidentes. Posteriormente, cuando las circunstancias políticas son apropiadas, los 'comunicadores llave' así promovidos, inician la etapa de prédica desembozada, en función directa de la ideología subversiva. Un ejemplo típico de un 'comunicador llave' es el caso de Mercedes Sosa, quien hábilmente promocionada a través de distintos medios de comunicación, incursiona actualmente desde España, paralelamente a su actuación artística, en problemas referidos a la situación interna de nuestro país, desde un punto de vista ideológico marxista. ${ }^{28}$

Según el informe ese material discográfico de contenido subversivo y/o disolvente, registra un crecimiento sostenido hasta el año 1975, decrece obviamente en 1976 y al año siguiente "es prácticamente nulo como consecuencia de que los sellos grabadores han sido alertados convenientemente y evitan verse comprometidos con dicho material". ${ }^{29}$ No obstante la desaparición de lo que denominan sin eufemismos "disco guerrilla", los servicios de inteligencia siempre necesitan, ideológicamente un "blanco" y burocráticamente una función para su reproducción, lo que queda diáfanamente demostrado en la apreciación final:

De no adoptarse medidas que tiendan a impedir la producción y/o distribución de lo que bien puede llamarse 'DISCO GUERRILLA', se aprecia que este medio de comunicación masivo continuará siendo utilizado por la subversión para lograr sus objetivos en el área psicosocial. ${ }^{30}$

Los "asesores literarios y musicales" de los servicios de inteligencia silenciaron esos sonidos para toda una generación, sin embargo no lograron arrancarlos definitivamente de los corazones de la cultura popular. Allí la memoria hizo su trabajo tenaz. Como escribió María Elena Walsh y cantó Mercedes Sosa en un recital antológico durante la transición a la democracia: "gracias doy a la desgracia y a la mano con puñal porque me mató tan mal, y seguí cantando." Aunque hay que recordarlo, también como dice la canción: era una sobreviviente.

28 Antecedentes ideológicos de artistas nacionales y extranjeros que desarrollan sus actividades en la República Argentina, p.291.

29 Antecedentes ideológicos de artistas nacionales y extranjeros ..., p.292.

30 Antecedentes ideológicos de artistas nacionales y extranjeros ..., p.292. 


\section{EI Ensayo y las Ciencias Sociales latinoamericanas: Las Venas Abiertas de América Latina}

El ensayo ha sido una forma privilegiada de expresión en América Latina. Probablemente uno de los más exitosos en términos de difusión fue Las Venas Abiertas de América Latina, del uruguayo Eduardo Galeano, texto emblemático de los años setenta, que, desde su primera edición, en 1971, no ha dejado reimprimirse. Este best seller ha sido a la vez uno de los libros más reimpresos de la historia de la ensayística (probablemente las reimpresiones superen el centenar entre legales e ilegales) y también uno de los más prohibidos. Texto manifiestamente escrito "para conversar con la gente", de inexcusable factura política y poética, Las Venas Abiertas fue uno de los tantos libros sometidos al análisis de los servicios de inteligencia argentinos. Conforme a la estructura antes nombrada, el libro "Propicia la difusión de ideologías, doctrinas o sistemas políticos, económicos e o sociales marxistas tendientes a derogar los principios sustentados por nuestra Constitución Nacional". Esta apreciación se basa en:

a) Actitudes o expresiones positivas o de apología, adhesión y/o afirmación hacia:

El Tercer mundo.

La lucha de clases.

Apología de la revolución cubana, la que 'engendrara la nueva sociedad instaurada por Fidel Castro, Che Guevara, etc.', dando como ejemplo algunas de sus medidas fundamentales: la reforma agraria de 1959, la política azucarera.

Citas de Marx, Mandel, Gunder Frank, Engels, Che Guevara, Fidel Castro, Perón, Jorge Abelardo Ramos, Lenin.

Exaltación de Tupac Amarú como 'padre de todos lo pobres y de todos los miserables desvalidos y como caudillo del movimiento revolucionario de mayor envergadura' (pág.67), quien dijera: 'campesino! El patrón ya no comerá más tu pobreza' (pág.69) (...).

La nacionalización de la producción del cobre por Salvador Allende 'para evitar el saqueo norteamericano' (...).

b) Actitudes negativas o de detracción y/o crítica hacia:

El Imperialismo (el Imperio al referirse a EE.UU)

Las clases dominantes

La oligarquía, el capitalismo

El control de la natalidad como política de EE.UU a aplicar en América Latina (...)

La conquista 'devastadora' de los españoles.

La Iglesia y la monarquía española y europeas en general desde el comienzo de la conquista y colonización.

El exterminio de los indios por los conquistadores.

La propiedad privada.

La explotación del hombre por el hombre, que motivó el sistema de 'producción capitalista' (cuyo origen es la 'esclavitud' y la 'trata de negros'). 
El presidente Onganía y las 'oligarquías latifundistas' del país.

El petróleo como la riqueza monopolizada por el sistema capitalista. ${ }^{31}$

Como vemos, en la hermenéutica de los asesores literarios el rango de la apología o la detracción es muy amplio. En principio la sola expresión "Tercer Mundo" es digna de señalamiento, aún ausente de adjetivación o precisión (por ejemplo "las luchas de liberación del Tercer Mundo"), basta sólo con la frase para argumentar la calificación. Por otra parte, la ecléctica enumeración de los autores elegidos para ejemplificar las citas también es reveladora. Si bien Marx, Engels, Mandel, Gunder Frank, el Che Guevara están claramente instalados en coordenadas de un genérico del marxismo (y la diferenciación entre pensadores y políticos aquí es menor), el clivaje que permite deconstruir parte de la lógica del "anticomunismo" está dada por dos políticos: Juan Domingo Perón (en el polo negativo del binarismo característico de esta lógica interpretativa) y Juan Carlos Onganía (denominado "presidente", no quien encabezara el primer golpe institucional de las FFAA en 1966) en el lado positivo de la valoración de la dictadura. Consideramos, aún embrionariamente, que esas caracterizaciones contribuyen a delinear el amplio perímetro de lo considerado "subversivo" por la dictadura militar, categoría mucho más amplia que el genérico "comunismo" o "marxismo". Y esto se profundiza en las conclusiones del informe que puntualizan el "carácter materialista del libro" y "la concepción marxista sobre los medios de producción" pero también y más sutilmente:

Se podría observar que, en forma imperceptible, queda disminuida o soslayada la idea o concepto de nación, para entrar directamente en el análisis económico y social entre 'explotadores y explotados'.

Si bien el libro está basado en hechos y circunstancias reales y su fundamentación es bastante extensa, la utilización de estos elementos es tendenciosa y observada desde el punto de vista materialista (marxista) ya mencionado, donde la unilateralidad lleva a la causalidad a desvirtuarse y diluirse.

Por lo expuesto y, debido a que dicho libro constituye un elemento de enseñanza y adoctrinamiento marxista (aunque no se defina expresamente) que puede tornarse peligroso en caso de llegar a manos inexpertas o de no iniciados, se propone la calificación mencionada en A) por atentar contra los principios sustentados por nuestra Constitución Nacional. ${ }^{32}$

De "forma perceptible" es claro que la frase "queda disminuida o soslayada la idea o concepto de nación" es uno de los considerandos más decisivos. No es éste el lugar de discusión de la factura conceptual de Las Venas Abiertas, más afín al binomio "imperialismo-nación" (en una de las versiones de la denominada Teoría de la Dependencia) que a la lógica

31 Archivo DIPBA, Mesa Referencia, Legajo n.17753, sin número de folio, 1977.

32 Archivo DIPBA, Mesa Referencia, Legajo nº.17753, sin número de folio, 1977. 
explotadores-explotados. Nuevamente la única idea de nación legítima es aquella que señaláramos al comienzo como parte de las autojustificaciones de la dictadura. Además, hay otra noción que nos parece que recorre transversalmente los análisis: la idea del valor del libro "en manos inexpertas o de no iniciados". Nuevamente esa teoría hipodérmica antes señalada.

\section{Las Ciencias Sociales latinoamericanas}

La producción sobre la región por parte de los cientistas sociales en la década de 1960 describe un doble movimiento: por un lado, la profesionalización de las ciencias sociales, sobre todo la sociología, a partir de la creación de carreras universitarias, centros de investigación, espacios de intercambio académico, revistas culturales y científicas. Por otro, las condiciones sociohistóricas latinoamericanas (la Revolución Cubana, el foquismo, el "compromiso social" de los intelectuales con la revolución, el "boom" de la narrativa latinoamericana) Ilevó a los cientistas sociales a plantear temas fundacionales: el populismo, los límites del desarrollismo, la "teoría de la dependencia" (en su versión modoproduccionista o circulacionista), la revolución (nacional, socialista) es decir, los alcances de la transformación social y el rol de las ciencias sociales en ella. ${ }^{33}$

Como hemos trabajado en otra oportunidad, ${ }^{34}$ en la segunda mitad del siglo XX, a partir de la creación de la CEPAL (1947) y su fortalecimiento en 1950, sorteando la oposición de los Estados Unidos y apoyándose en el fuerte apoyo de los gobiernos de Chile y, sobre todo, de Brasil, la CEPAL adquiere dimensión regional en el proceso de construcción institucional y teórica de las ciencias sociales latinoamericanas. Un proceso en el que interactúan institutos universitarios, centros académicos independientes y organismos internacionales regionales, como, amén de la propia CEPAL, la Facultad Latinoamericana de Ciencias Sociales (FLACSO) y el Consejo Latinoamericano de Ciencias Sociales (CLACSO), creados en 1957 y 1967 , respectivamente. ${ }^{35}$ Se trata de un entramado en el que los actores involu-

33 Una bibliografía muy sucinta: BLANCO, Alejandro. Gino Germani: las ciencias del hombre y el proyecto de una voluntad política ilustrada Punto de vista, n.62, noviembre de 1998; BLANCO, Alejandro. La sociología por escrito: un episodio de su historia intelectual. Revista de Ciencias Sociales, Departamento de Ciencias Sociales, Universidad Nacional de Quilmes, octubre de 2002. NOÉ, Alberto. Utopía y desencanto. Creación e institucionalización de la Carrera de Sociología en la Universidad de Buenos Aires: 1955-1966. Buenos Aires: Miño y Dávila Editores, 2005; GERMANI, Ana Alejandra. Gino Germani. Del antifascismo a la sociología. Buenos Aires: Editorial Taurus, 2004; ANSALDI, Waldo. La búsqueda de América Latina: entre el ansia de encontrarla y el temor de no reconocerla. Teorías e instituciones en la construcción de las ciencias sociales latinoamericanas. Buenos Aires: Instituto de Investigaciones Gino Germani/Universidad Nacional de Buenos Aires, 1991; GILMAN, Claudia. Entre la pluma y el fusil. Buenos Aires: Siglo XXI, 2003.

34 FUNES, Patricia y ANSALDI, Waldo. Viviendo una hora americana. Acerca de rupturas y continuidades en el pensamiento en los años veinte y sesenta. Cuadernos del CIHS, Facultad de Humanidades y Ciencias de la Educación. Universidad Nacional de La Plata, Nueva Época, n.4, p.13-75, segundo semestre 1998.

35 Sobre el papel de CEPAL, FLACSO y CLACSO en la construcción de las Ciencias Sociales latinoamericanas, véase ANSALDI, Waldo. La búsqueda de América Latina. Entre el ansia de encontrarla y el temor de no reconocerla. 
crados actúan entre sí con las sociedades de la región, tensionado por las relaciones entre ciencia y política.

Esto no era ignorado por los servicios de inteligencia, a juzgar por los cuantiosos informes de inteligencia sobre obras clásicas de las ciencias sociales de la región (obras de Gino Germani, José Aricó, Fernando Henrique Cardoso, Enzo Faletto, Theotonio Dos Santos, Vania Bambirra, André Gunder Frank, Alberto Pla, Aníbal Quijano, Agustín Cueva, Octavio lanni, Ruy Mauro Marini, Francisco Weffort, entre otros), sobre centros de investigación (CEPAL, FLACSO, CLACSO), revistas (Pasado y Presente, Nueva Sociedad, entre otras), conferencias y encuentros académicos, editoriales (CEAL, Siglo XXI).

Por ejemplo, en el informe del libro América Latina: Economía y Política, compilado por James Petras, ${ }^{36}$ se señala: "es conveniente mencionar que, varios de los autores del presente libro pertenecen a FLACSO (Facultad Latinoamericana de Ciencias Sociales) de conocida trayectoria marxista". ${ }^{37}$ Otro tanto con CLACSO (Consejo Latinoamericano de Ciencias Sociales), incluso con algunos papers de la CEPAL.

Cualquier libro ligado al campo de la llamada Teoría de la Dependencia fue prohibido, incautado, quemado, retirado de las bibliotecas. Muchas páginas de estos legajos que estamos analizando en esta primera instancia de la investigación lo demuestran. Un ejemplo: el artículo Ciencia y conciencia social de Fernando Henrique Cardoso y Francisco Weffort, incluido en el libro América Latina: dependencia y subdesarrollo. ${ }^{38}$ Según los asesores literarios de la SIDE, "dos señalamientos de la obra, nos parecen representativos de la mayoría de las fundamentaciones para su prohibición":

La obra en cuestión parte, según sus autores, de la necesidad de estudiar la realidad social (...) para lo cual consideran necesario la formación de una "nueva generación" de profesionales que tengan un conocimiento más profundo de la realidad nacional, regional, y latinoamericana en general. Como obstáculos a dichos cambios son enunciados: a) la poca difusión y disponibilidad de "nueva literatura"; b) el lento proceso de 'latinoamericanizar' las Ciencias Sociales. ${ }^{39}$

Como señala Ansaldi,

Teorías e instituciones en la construcción de las ciencias sociales latinoamericanas. Cuadernos/1, Buenos Aires, Instituto de Investigaciones/Facultad de Ciencias Sociales/UBA, especialmente p.16-17 y 65-77, 1991.

36 PETRAS, James. (org.) América Latina: Economía y Política. Chile: Editorial Periferia, 1972.

37 Los autores consignados son: Marcelo Cavarozzi, Alberto Couriel, Luis Quirós Varela, José Serra, Jorge Tapia Videla, María C. Tavares y René Zavaleta Mercado. Archivo DIPBA, Mesa Referencia, Legajo $\mathrm{n}^{\circ} .17518$, sin número de folio.

38 CARDOSO, Fernando Henrique y WEFFORT, Francisco. América Latina: dependencia y subdesarrollo. Costa Rica: EDUCA, 1976.

39 Archivo DIPBA, Mesa Referencia, legajo n.18518, p.90. 
(...) la construcción del conocimiento científico social latinoamericano, la práctica de las ciencias sociales y la aparición, consolidación e incluso desaparición de instituciones a ellas dedicadas han sido siempre partes de un proceso en el que el conocimiento ha apuntado a la transformación de las sociedades. También, a menudo, el intento de impedir la práctica de estas ciencias está relacionado con la voluntad de impedir tal transformación o, por lo menos, impedir aquella que afecta a grupos sociales dominantes. ${ }^{40}$

El lento pero sostenido proceso de latinoamericanización de las Ciencias Sociales era visto con preocupación y señalado como altamente peligroso. Debido a lo extenso de la obra y a la gran cantidad de autores (24 autores) se hizo una selección de características comunes a todos los ensayos:

(...) encuadrados dentro del marco teórico de la dependencia, pero de los cuales se destacan, por su fuerte carácter apologético: Diez años de insurrección en América Latina de Vania Bambirra, que desarrolla la organización y movilización de las agrupaciones guerrilleras en América Latina (...), Ciencia y conciencia social de F. H. Cardoso y F. C. Weffort, que hace un análisis de las interrelaciones de 'dominación y subordinación en los países dependientes', y por último La dependencia estructural, de Octavio lanni que considera que dicha dependencia no sólo se encuentra en la esfera económica sino también política e ideológica. ${ }^{41}$

Y no sólo los teóricos de la teoría de la dependencia eran analizados o la Sociología y los sociólogos manifiestamente comprometidos con la revolución. Tomemos, por caso, al padre fundador de la Sociología en Argentina: Gino Germani. El ya clásico libro Populismo y contradicciones de clase en Latinoamérica, ${ }^{42}$ que contiene artículos de Gino Germani, Torcuato Di Tella y Octavio lanni, también está en el índex por "propiciar la difusión de ideologías, doctrinas o sistemas políticos, económicos e o sociales marxistas tendientes a derogar los principios sustentados por nuestra Constitución Nacional", ya que:

En los tres trabajos se examinan [las experiencias] del "Populismo" en muchos de sus aspectos, formas y aplicaciones prácticas (...) y siempre en relación y comparación con el mundo revolucionario, socialista o marxista de los que usa algunos de sus elementos (...).

No es ésta la instancia de realizar el análisis del análisis, baste recordar la herencia funcionalista (no marxista) del propio Germani, quien había creado la Carrera de Sociología de la Universidad de Buenos Aires en 1957. Las carreras de Sociología fueron particularmente perseguidas, prohibidas, incluso cerradas durante la última dictadura militar que se ensañó parti-

40 ANSALDI, Waldo. Viviendo una hora americana, p.66.

41 ANSALDI, Waldo. Viviendo una hora americana, p.91.

42 GERMANI, Gino. Populismo y contradicciones de clase en Latinoamérica. México: ERA, 1973 
cularmente con los libros, las revistas (incluso las fotocopias) referidas a las interpretaciones de los años sesenta y setenta de las ciencias sociales latinoamericanas. Las consecuencias aún están vigentes. En este caso, la transmisión fue más dificultosa, el exilio, la cárcel y la salida de la mayoría de los profesores de la Universidad fue absolutamente masivo. También los hubo desaparecidos. En la página Web de la Carrera de Sociología de la UBA, que este año celebra su 50 aniversario, pueden leerse las reflexiones de una socióloga perteneciente a esa generación de fundadores de la sociología en Argentina de los años sesenta:

\begin{abstract}
Aún hoy no sabemos bien dónde quedaron todos los libros arrancados de los estantes de la gran Biblioteca de Sociología de los años 60 y 70 y nos cuesta un enorme esfuerzo reconstruir la historia. Como efecto de esa tierra arrasada se hundió en el olvido y la confusión toda la historia fundacional de nuestra Carrera, incluido Germani. Sin embargo no pudieron con nosotros, ni siquiera dos dictaduras. Por lo cual yo diría que Germani, el 'tano', ganó. Su obcecación nos enseñó a investigar, a ser rigurosos, a fundamentar con datos nuestras afirmaciones, y la realidad, no él, nos obligó a ser menos intolerantes. Y si hemos aprendido que no podemos hacer la revolución con la sociología, también sabemos hoy que no hay nada más revolucionario que el conocimiento verdadero. ${ }^{43}$
\end{abstract}

No queremos adelantar muchas conclusiones. Cabe en el futuro reflexionar acerca de ese artesanal trabajo de escucha (en el caso de los discos es en tiempo real), mecanografiado de las letras, traducciones de varios idiomas, redacción, de esa "burocracia del mal" especializada en el análisis y censura del campo cultural. También cabe enunciar la crítica a ciertos sentidos comunes, que en ocasiones tienden a trivializar bajo estereotipos del orden de la "ignorancia" o la "negligencia" los alcances intelectuales de las dictaduras institucionales de las fuerzas armadas. Fuerza e ideas. Sin duda la primera primó sobre la segunda, sin embargo esa fuerza construyó un campo ideocrático que, aunque modesto en sus consideraciones, se fortaleció e intentó autolegitimarse alentado por un conjunto de analistas profesionales provenientes sin duda del campo de las ciencias sociales (traductores, sociólogos, críticos literarios, filósofos, comunicadores) que elaboraron en las sombras fundamentaciones de refuerzo acerca de la culpabilidad/peligrosidad a priori de las representaciones simbólicas de América Latina.

Es el presente trabajo un adelanto de una investigación que está en sus albores, pero -a pesar de la sabia y optimista evaluación de la colega-, la herencia de esa destrucción aún nos atraviesa. La trasmisión de genealogías, formas de pensamiento y categorías, incluso sociabilidades, fue más

43 IZAGUIRRE, Inés. Acerca de un maestro, Reseñas de Gino Germani. Buenos Aires: Instituto de Investigaciones Sociales "Gino Germani"/Facultad de Ciencias Sociales/Universidad de Buenos Aires. 
difícil sin esos libros y esos investigadores. Es más, no sería aventurado afirmar que las ciencias sociales argentinas se alejaron hasta hoy de América Latina. Y probablemente algo similar haya ocurrido en el resto de la región por un empeño sistemático de las sucesivas dictaduras militares. Pero eso, ameritaría otro artículo. 